\title{
Educação Adventista: realidade em expansão
}

\author{
Adventist Education: a reality in expansion
}

\section{Douglas Menslin*}

Centro Universitário Adventista, São Paulo, SP, Brasil

\section{Resumo}

A Rede Educacional Adventista completa no ano de dois mil dezesseis, cento e vinte anos de sua chegada em solo brasileiro. De caráter confessional, baseada nas matrizes educacionais norte-americanas e influenciada pelo período de expansão internacional das denominações religiosas protestantes consideradas históricas, traz em sua gênese o conceito de educação/missão, onde a fé religiosa e o papel da educação buscam a transformação do ser humano. Neste estudo é apresentado o desenvolvimento educacional e sua expansão como rede de ensino confessional.

Palavras-chave: Educação. Educação Confessional. Educação Adventista.

DM: Doutor em Educação, e-mail: douglas.menslin@gmail.com 


\section{Abstract}

The Seventh Day Adventist educational system, in the year of two thousand and sixteen commemorates one hundred and twenty years of its arrival in Brazil. Its confessional character, based on the foundations of its north-American counterparts and influenced by the international expansion of the historic protestant denominations, brings on its core the value of education/mission, where religious faith and the role played by education pursue the transformation of the human being. This study explores the development and expansion of this network of confessional education.

Keywords: Education. Confessional education. Adventist Education.

\section{Introdução}

A Rede Educacional Adventista, de caráter confessional, está vinculada diretamente à Igreja Adventista do Sétimo Dia, que é mantenedora do sistema educacional adventista. Em 2015, essa rede atendeu 1.673.828 alunos em 7.804 unidades escolares de ensino básico até universidades, com 84.997 professores $^{1}$ e se faz presente em 145 países ao redor do mundo. A concepção filosófica de educação, atrelada a uma ideologia baseada no cristianismo, integrando educação com a missão religiosa da denominação, traz relevância para um estudo que visa compreender como este sistema, que acaba de completar 120 anos no Brasil, começou e cresceu, gerando contribuições para a educação confessional de nosso país.

A educação adventista chegou ao Brasil como parte da empreitada missionária de uma recém formada denominação protestante (1844-1860) que se originou no norte dos Estados Unidos. E, apesar de iniciar as atividades educacionais quase que concomitantemente com o estabelecimento de grupos de pessoas que estavam se tornando adeptos da denominação,

1 Dados coletados no Relatório Estatístico do Departamento de Educação da Igreja Adventista do Sétimo Dia. Disponível em: <http://education.gc.adventist.org>. 
a penetração do adventismo no Brasil, aconteceu, primariamente, com o envio de missionários vendedores de literaturas religiosas.

Depois que os vendedores de livros despertaram interesse suficiente dos ensinos adventistas e relataram a existência de um número considerável de guardadores do sábado, os líderes da denominação nos Estados Unidos começaram a enviar pastores para batizarem os novos convertidos e também para organizar as primeiras igrejas. O primeiro pastor ordenado a chegar ao Brasil foi Frank H. Westphal que, partindo dos Estados Unidos em 1894, estava incumbido de organizar as comunidades adventistas na Argentina, no Uruguai e no Brasil.

Greenleaf (2011, p. 41) descreve que após um mês da chegada de Westphal ao Brasil, que ocorreu em fevereiro de 1895, ele teve a oportunidade de realizar mais de 20 batismos, "sendo que o primeiro deles foi de Guilherme Stein Jr., filho de imigrantes da Suíça e Alemanha”, que, segundo Vieira (1995, p. 134), "com o batismo de Guilherme Stein Jr. em Piracicaba, iniciou-se formalmente a história da Igreja Adventista do Sétimo Dia" no Brasil. O nome de Guilherme Stein Jr. é relevante para a educação adventista, não só pelo fato de ser o primeiro converso da denominação, mas porque, como será apresentado abaixo, ele tornou-se o primeiro professor e diretor das três primeiras escolas adventistas que iniciaram suas atividades no Brasil.

Importa dizer que os líderes da denominação na América do Norte, em especial os que eram responsáveis pela Comissão de Missões Estrangeiras, ao tomarem conhecimento da variedade linguística que existia entre os imigrantes que estavam chegando no Brasil, viam a educação como uma forte ferramenta para o proselitismo religioso. Sobre esse pensamento, Greenleaf (2011, p. 36) comenta que os líderes da denominação "acreditavam que, ao expor as crianças à educação adventista, o acesso aos pais seria desobstruído. Tratava-se de uma sugestão clara de que a educação adventista poderia consistir numa poderosa ferramenta evangelística”.

Os membros da nova denominação constituída no Brasil, usaram as escolas como meio de alcançar o público, porém, esse não era o único objetivo, para Greenleaf (2011, p. 56), existiam outros fatores que foram levados em conta para abertura de escolas, pois também "consideravam 
que a vantagem da educação era a conservação da juventude na igreja e a preparação de obreiros".

Transcorrido apenas um ano da oficialização da denominação adventista em solo brasileiro, H. F. Graf, que fora responsabilizado pela evangelização dos imigrantes alemães nos estados do Paraná, Santa Catarina e Rio Grande do Sul, sente a necessidade de iniciar um projeto de evangelização através da educação e, graças a sua visão, três escolas iniciaram suas atividades nos anos seguintes. Mas para isso era necessário encontrar um professor que fosse fluente na língua oficial do país, além de atender os filhos de imigrantes em seus respectivos idiomas. Por conhecer as qualidades do jovem Guilherme Stein Jr., que era fluente em três idiomas além de ter estudado durante cinco anos no Colégio Internacional de Campinas $^{2}$ de origem presbiteriana, Graf entende que este era o nome indicado para assumir a responsabilidade de iniciar o projeto educacional da denominação, e assim, o convida para ser o primeiro professor e diretor do primeiro colégio adventista em solo brasileiro.

A cidade escolhida para o início das atividades educacionais adventista foi Curitiba. E isto não foi por acaso. Na época, Curitiba começa a se destacar como uma cidade progressista republicana, nomeada em 1812 como sede de comarca, passa a ser a rota dos viajantes que cruzavam o país em direção ao sul. O progresso cultural e educacional da cidade, somados a localização de fácil acesso tanto para quem vinha do sul ou de São Paulo, mais a composição da população, constituída em sua base de imigrantes alemães foram determinantes para a escolha da cidade para a abertura da primeira escola adventista no Brasil.

A data de abertura da primeira escola adventista foi 1 o de junho de 1896 e foi nomeada como Colégio Internacional de Curitiba ${ }^{3}$.

Sobre o início dessa primeira escola, o próprio Guilherme Stein Jr., deixa registrado em seus escritos:

2 O Colégio Internacional de Campinas, de origem presbiteriana, era considerado um dos mais influentes colégios protestantes da época, além de ser o primeiro colégio protestante a funcionar no Brasil.

3 Possivelmente a escolha desse nome tenha sido influenciada pelo Colégio Internacional de Campinas, pioneiro da educação protestante no Brasil. Como Guilherme Stein Jr. foi aluno daquela instituição, é possível que ele tenha indicado esse nome, haja visto que o colégio adventista também trabalharia com alunos de várias etnias e em mais de um idioma. 
Curitiba era já naquele tempo o que podemos chamar quase uma cidade universitária, com grandes colégios, mas seguindo ainda a rotina do sistema de soletração nas escolas primárias. A nossa escola progrediu rapidamente, o que devemos em parte ao sistema fonético do professor mineiro Felisberto de Carvalho, que introduzimos e defendemos malgrado a oposição dos colégios, como o grande Colégio Alemão ${ }^{4}$, cujo corpo docente defendia o sistema hoje arcaico, tendo nós de sustentar uma disputa pelo jornal alemão 'Der Beobachter' (O Observador) ${ }^{5}$, defendendo o novo sistema. A escola, que começou com meia dúzia de alunos, acusou ao cabo de seis meses uma matrícula de mais de 120 alunos (VIEIRA, 2011, p. 17).

No Colégio Internacional de Curitiba ministravam-se aulas em alemão e em português. Segundo Vieira (1995, p. 149) "durante os oito anos de sua existência, chegou a ter matrícula anual superior a 400 alunos". Gross (1996, p. 47) comenta que "as mais ricas e tradicionais famílias de Curitiba ali matriculavam os seus filhos. As aulas continuaram sendo dadas em alemão, com três aulas semanais em português”. Mas não era somente por apresentar um ensino bilíngue que a sociedade curitibana estava enviando seus filhos para o Colégio Internacional, mas sim, pela qualidade de um ensino de vanguarda. Peverini (1988, p. 108) ao falar sobre a qualidade de ensino diz que "este colégio estava provido do melhor equipamento didático da cidade, e do estado, e possivelmente de todo o país, pois possuía projetores diapositivos, microscópio e outros elementos avançados para sua época", além de contar com um laboratório de ciências com todas as vidrarias possíveis. Essa visão de qualidade de ensino, partia de seu diretor Paul Krämer, que mais tarde seria o fundador do Laboratório Krämer, voltado para a área farmacêutica.

É importante ressaltar que diferentemente das intenções de preservação da fé por parte dos filhos dos pais convertidos ao adventismo norte americano, que fundava escolas para manterem seus filhos afastados da influência de conceitos não cristão ensinados nas escolas

4 Uma referência ao Deutsche Schule, a escolar alemã de maior destaque nesse período na cidade de Curitiba, como pode ser analisado na tese doutoral de Regina Maria Schimmelpfeng de Souza (2006), cujo estudo é "Deutsche Schule, a Escola Alemã de Curitiba: um olhar histórico (1884-1917)".

5 Para Marcassa (1989, p. 140), Curitiba na época contava com expressivo número de periódicos em língua alemã. 0 Der Beobachter havia sido fundado em 1889, sete anos depois do Deutsche Wochenblatt, que foi o primeiro jornal alemão a circular em Curitiba, a partir de 1882.

Rev. Pistis Prax., Teol. Pastor., Curitiba, v. 9, n. 3, 666-683, set./dez. 2017 
públicas, essa escola não foi fundada para atender os filhos dos pais recém convertidos ao adventismo. Segundo os registros de Krämer (1909, p. 256), no ano de 1899 "somente dois alunos eram filhos de adventistas, quanto mais de uma centena eram não adventistas". Isso quer dizer que a maioria era composta de pessoas de outras comunidades religiosas. Contudo, a metodologia utilizada nesse projeto embrionário de educação confessional era composta de conceitos religiosos da fé adventista.

\section{A expansão da educação adventista}

Ao analisar o desenvolvimento da educação adventista desde o seu início até o presente momento, é possível dividir essa história de cento e vinte anos em pelo menos três períodos distintos - pioneirismo, estruturação e adaptação.

\section{a. 0 pioneirismo da educação adventista no Brasil - 1896-1915}

A educação adventista deu o primeiro passo para estabelecer suas atividades educacionais no sul do Brasil, mas não poderia permanecer apenas atendendo a uma comunidade, levando em conta que seu objetivo era auxiliar na expansão da denominação, através de preservação da fé das crianças e também como meio de difusão da mensagem evangelizadora da denominação.

O prof. Guilherme Stein Jr. é convidado para continuar a expansão educacional, auxiliando na abertura de pelo menos mais duas escolas, uma em Gaspar Alto, em Santa Catarina, no ano de 1897, e outra em Taquari, no Rio Grande do Sul, em $1902^{6}$.

6 Os detalhes sobre a abertura de várias escolas por Guilherme Stein Jr. bem como sua contribuição na consolidação tanto da educação como da denominação adventista é descrita na obra biográfica de Vieira (1995), cujo título é Vida e Obra de Guilherme Stein Jr. 
Com a abertura da escola de Gaspar Alto, inicia-se novo projeto educacional para os adventistas - as escolas paroquiais ${ }^{7}$ - pois, como apresenta Rabelo (1990, p. 37), Gaspar Alto "além de ser o palco da organização da primeira Igreja Adventista do Sétimo Dia no Brasil, é também ali organizada a primeira escola paroquial, em 1897".

Azevedo (2004, p. 32), compartilha que o período compreendido entre 1896 e 1915 foi caracterizado "pelos esforços iniciais dos pioneiros do movimento adventista no Brasil em abrir igrejas mas também escolas". Os pioneiros tinham a visão de que a escola era, em essência, uma forma dinâmica e sólida de expandir a Igreja Adventista no Brasil. O mesmo autor argumenta que nos "dez anos seguintes, a Igreja Adventista foi penetrando em outros estados e o sistema educacional adventista foi, consequentemente, se expandindo". Levando em consideração que era um momento de implantação de uma nova cultura religiosa em solo brasileiro, "o período foi caracterizado pelo arrojo e pela notável percepção de que a educação adventista seria um valioso instrumento de sólida expansão da igreja em um país onde ela era ainda totalmente desconhecida" (op. cit, p. 33).

\section{b. A estruturação da educação - 1916 -1970}

Embora pesquisas realizadas sobre o desenvolvimento da educação adventista no Brasil apresentem subdivisões para esse período histórico (1916-1970) ${ }^{8}$, por questão de espaço optamos em sintetizar o desenvolvimento educacional adventista nesses anos num único bloco.

Necessário lembrar que o Brasil nesse período passava por mudanças tanto no sistema de governo, como na implantação de políticas públicas voltadas para as áreas sociais e educacionais que demarcaram o estabelecimento de um novo olhar na construção de sua cultura como

7 As escolas paroquiais eram mantidas pelas igrejas locais, onde por interesse próprio iniciavam as atividades escolares visando atender as necessidades dos filhos dos novos conversos, por isso eram pequenas em suas estruturas e em número de alunos. Em alguns casos, as escolas paroquiais também tinham o objetivo de preparar jovens para servirem como obreiros de tempo integral da denominação, como no caso da escolar de Gaspar Alto.

8 Azevedo (2004) divide o desenvolvimento da educação adventista no Brasil em oito fases. Já Stencil (2006), ainda acrescenta mais um período, relacionado ao desenvolvimento do ensino superior. 
nação, o que, de modo direto, influenciou a estruturação da educação adventista em solo brasileiro.

Entre os anos vinte e a década de sessenta daquele século, a educação adventista estabeleceu como prioridade a atuação em duas frentes: a formação de líderes para a denominação e abertura de escolas paroquiais junto às igrejas e comunidades de novos conversos da denominação.

Segundo dados estatísticos apresentados por Azevedo (1973), nos anos finais da década de cinquenta existiam mais escolas adventistas do que igrejas adventistas no território brasileiro. Isso representa que, antes de se abrir uma nova igreja, a denominação priorizava a abertura de uma escola, por acreditar que a partir das escolas seria mais fácil alcançar os adultos. Porém, os dados coletados também apresentam que ao iniciar a década de sessenta, a denominação adventista se depara com um crescimento maior em número de membros e igrejas constituídas em relação ao número de escolas e alunos matriculados. Se uma década antes existiam mais escolas do que igrejas, dez anos depois a educação adventista representava $75 \%$ do total de igrejas da denominação em solo brasileiro.

Alguns fatores são determinantes para a compreensão dessa realidade. O país estava vivendo nas décadas de sessenta e setenta um período de urbanização, e consequente êxodo rural. Como lembra Martine (1990, p. 67), a partir de meados dos anos 60 "iniciou-se uma progressiva e sem precedentes desruralização e concentração urbana derivadas de transformações sociais ocorridas nesse período".

No contexto adventista, as igrejas e, consequentemente, as escolas eram abertas em pequenas cidades, ou em regiões rurais. Segundo Hosokawa (2001, p. 47), “a maior penetração dos missionários adventistas aconteceu no meio rural e entre os alemães nos primeiros anos do adventismo no Brasil", o que caracterizou ser um movimento religioso voltado a pequenas comunidades rurais com etnias definidas. E, diante do êxodo rural e o crescimento urbano, essas escolas rurais ou em pequenos municípios, não supriam mais a necessidade da igreja, pois não acompanharam o seu crescimento, agora, em centros urbanos emergentes.

Contudo, para manter os propósitos estabelecidos no ideário adventista de educação, levando em conta que o número de escolas era insuficiente para atender a demanda do crescimento urbano, e que essas 
escolas ofereciam apenas a educação primária, gerando assim uma ruptura na formação acadêmica de seus alunos que, para continuarem estudando tinham que migrar para outras escolas não adventistas que ofereciam o segmento de estudos ginasial, a instituição opta por abrir colégios de internato, visando oportunizar o envio dos filhos dos membros da denominação a essa modalidade de educação. Esses colégios recebiam alunos de ambos os sexos, e de todas as regiões do Brasil.

Outro fator importante no estabelecimento de escolas adventistas na modalidade de ensino de internato foi que essas se transformaram num marco importante para a formação de líderes para a denominação. Hosokawa (2001, p. 64) analisa que com o crescimento do número de novos conversos ao adventismo, em solo brasileiro, e com a pouca presença de missionários estrangeiros enviados ao Brasil, era necessário criar centros de formação de novos líderes.

Já no contexto de preparo de mão de obra voltada para o trabalho educacional nas escolas paroquiais da denominação, a abertura dessas escolas preparatórias de internato foi fundamental para a consolidação tanto do sistema educacional como, também, da própria denominação, pois a maioria da sua liderança, quer seja composta de professores e administradores das escolas paroquiais ou mesmo como líderes religiosos dos templos e igrejas, obtivera sua formação inicial nessas escolas preparatórias.

Vale ressaltar que o primeiro internato Adventista do Brasil é estabelecido na cidade de São Paulo, no ano de 1915 - após duas tentativas embrionárias em Gaspar Alto, SC (1897) e em Taquari, RS (1903). Conhecido originalmente como Seminário Adventista, passou a denominar-se em 1923 como Colégio Adventista e, pelas pressões nacionalistas no período da 2a Guerra Mundial, muda o nome para Colégio Adventista Brasileiro em 1941. Em 1961, o nome foi novamente alterado para Instituto Adventista de Ensino. Em 2001, por decreto presidencial, transforma-se no Centro Universitário Adventista de São Paulo, sendo este, o maior centro de formação mundial da denominação adventista com matrícula superior a 18.000 alunos.

Como o interesse da educação nacional estava voltado para o ensino profissionalizante, os internatos adventistas se especializaram em oferecer cursos de formação profissional, principalmente nas áreas de saúde, ensino 
e finanças, fornecendo mão de obra especializada tanto para a denominação, como também no preparo dos alunos para se consolidarem no mercado de trabalho da época. Atualmente, a educação adventista é a rede de ensino confessional no Brasil que mais oferece opções de ensino na modalidade de internato para alunos de ambos os sexos.

Mas não foi apenas no segmento de ensino de internato que a educação adventista expandiu suas fronteiras, a decisão por abrir escolas de externato acompanhava a necessidade educacional do próprio país, apoiado nas ideias educacionais construídas a partir do movimento Escola Nova, que difundiu a partir de 1929, a necessidade de expansão democrática do ensino. Vale ressaltar que a proposta educacional defendida pela Escola Nova era uma educação laica e pública.

Após o final da $2^{\text {a }}$ Guerra Mundial, a rede adventista deu passos largos para a sua expansão, concentrando seus esforços na abertura de escolas primárias de quatro séries. Esse processo desenvolveu-se por cerca de três décadas, período áureo da expansão educacional adventista em solo brasileiro. $\mathrm{O}$ ensino não era exclusivo para alunos cujos pais frequentavam a igreja adventista, porém, a maioria dos alunos que estudava nessas escolas era de famílias que professavam a fé adventista.

Apesar de ser uma educação marcada de símbolos e crenças religiosas, as disciplinas seguiam um programa abrangente, com os conteúdos básicos exigidos pela educação oficial do estado, com disciplinas na área de exatas (matemática), humanas (português, alemão, artes, história, geografia), biológicas (ciências) e religiosas (ensino religioso).

Para Azevedo (2004, p. 35), o marcante crescimento desse período deveu-se ao compromisso dos líderes da denominação com o "ideal adventista de que junto a cada igreja deveria haver também uma escola. Esse ideal é na 
realidade um dos pilares da Reforma Protestante" ${ }^{\text {, }}$, onde todos os filhos de famílias cristãs deveriam mandar seus filhos para as escolas ${ }^{10}$.

Porém, ao aproximar os anos finais da década de 1960, a educação adventista não mais acompanhou o ritmo de crescimento da igreja e seus membros, existindo assim um distanciamento entre o número de membros e igrejas e o número de alunos e escolas. Além desse distanciamento, ocorre a principal crise no desenvolvimento educacional adventista, que estabeleceria novos rumos para a educação adventista e, também, colocaria em xeque as bases filosóficas de sua ideologia - a institucionalização do ensino como educação formal, tendo como base a implantação da Lei de Diretrizes e Bases 5692/71.

\section{c. A adaptação da Educação Adventista à cultura educacional - 1970-2015}

Como apresentado anteriormente, o Brasil dos anos sessenta atravessa um período de grandes mudanças, tanto de ordem política como econômica, que influenciariam diretamente o desenvolvimento educacional daquele período e dos anos posteriores. As mudanças organizacionais acontecem em meio a conflitos que geram construções e desconstruções de ideologias estabelecida e a estabelecer.

Embora o cenário político apresentasse um certo grau de instabilidade, os que governavam a nação buscavam criar uma estrutura econômica que trouxesse mais desenvolvimento para um país, que tentava estabelecer conexões capitalistas através de um modelo associadodependente com capital estrangeiro que, em seu bojo, traria consigo a cultura social desse modelo.

9 Weber em A Ética Protestante e o Espírito do Capitalismo (2007) aborda o desenvolvimento da Reforma Protestante, em suas diferentes raízes, e seu legado para a consolidação dos movimentos religiosos cristãos não católicos no estabelecimento do sistema social capitalista, tanto no continente europeu como no americano.

10 Martinho Lutero via a escola como meio de transformação social. Em 1530, no apelo que faz aos pais para que enviem os seus filhos à escola, Lutero explicita que o seu objetivo é o de que todas as crianças recebam uma educação formal cristã, ou seja, que todas, independentemente do tipo de família a que pertençam, frequentem a escola. Sendo assim, ele conclama os "filhos dos patrões" e os "filhos de gente pobre" para frequentarem a escolar (LUTERO, 1995, p. 342). 
O pano de fundo dessa tendência está baseado na teoria do capital humano, fundamentada a partir dos conceitos de economia e educação desenvolvido por Theodore Schulz (1967, p. 35), que defendia que a "educação torna as pessoas produtivas e a boa atenção à saúde aumenta o retorno do investimento em educação".

Para o cumprimento da nova legislação, buscou-se adequar as escolas do país na visão produtivista, por meio de uma pedagogia tecnicista que advogava uma reorganização do processo educativo, tornando-o mais objetivo e operacional e menos subjetivo e reflexivo.

Entre as principais regulamentações determinadas pela Lei 5.692/71 destacam-se a ampliação da obrigatoriedade escolar de quatro para oito anos, extinguindo a separação entre o ensino primário de quatro anos e ginasial de mais quatro anos, aglutinando em apenas um bloco de oito anos de ensino e, suprimindo o exame de admissão para o antigo ginásio; a criação da escola profissionalizante para o ensino do $2^{\circ}$ grau, com duração de três ou quatro anos; a inserção do ensino de Educação Moral e Cívica nas escolas; e a inserção de um currículo mínimo com disciplinas específicas para os anos finais do $1^{\circ}$ grau e em todo o período do $2^{\circ}$ grau (LIRA, 2010, p. 80).

Para o segmento privado da educação, as mudanças introduzidas pela nova legislação, trouxeram várias preocupações. Muitas dessas escolas ofertavam apenas o ensino primário com quatro séries, onde, posteriormente o aluno se prepararia para prestar o exame de admissão para ser aceito no antigo ginásio. Oferecer um programa contínuo de oito séries, acarretaria em um aumento de custos com professores específicos, além de estrutura física para atender as exigências estabelecidas. Isso geraria custos que o ensino privado, na sua grande maioria, não estava preparado (OLIVEIRA, 2002, p. 93).

Tudo indica que para a educação adventista a nova legislação foi um golpe duro para ser superado. Segundo Azevedo (2004, p. 36), a educação adventista no território brasileiro terminara o ano de 1970 com 321 unidades escolares, porém, "nos cinco anos seguintes, a perda foi devastadora, com o fechamento de 101 delas". Continua ele, "muitas escolas primárias adventistas de quatro séries, com poucas salas de aulas 
e área física insuficiente, não possuíam infraestrutura adequada para serem transformadas em escolas de 1o grau completo com oito séries".

Levando em conta que, quase na sua totalidade, as escolas adventistas existentes até esse período eram patrocinadas pelas igrejas locais, e que havia um incentivo por parte dos líderes religiosos para que todos os filhos (em idade escolar) dos membros da denominação, quer as famílias tivessem condições ou não de assumirem os custos de uma educação particular, deveriam manter seus filhos na escola da igreja, com o objetivo de manterem os valores religiosos na formação escolar dos mesmos, o valor arrecadado com mensalidades escolares nem sempre supria com os gastos que uma escola particular necessitava. Os recursos no geral eram conseguidos com arrecadação de fundos, doações e campanhas junto a famílias mais abastadas, que ajudavam inclusive pagando mensalidade de outros alunos além dos seus próprios, para garantir que nenhuma criança ficasse fora da educação confessional adventista.

Como adaptação ao processo educacional vigente é possível verificar que a educação adventista iniciou um programa de transformação e reestruturação de seu sistema e, durante os próximos 15 anos, até 1988, quando da promulgação da nova Constituição Federal, pode-se dizer que uma rede de ensino foi constituída. As escolas pequenas e, às vezes, multisseriadas, passaram a dispor de terrenos maiores, em outros casos, novas escolas começaram a surgir. Diretores e professores foram qualificados, e gradativamente, foram surgindo centenas de novas escolas adequadas ao plano de ensino fundamental de $1^{\circ}$ grau. A tabela 1 mostra o desenvolvimento desse processo e o crescimento da rede no período de 1970 a 1988:

Tabela 1 - Reestruturação da Educação Adventista - 1971-1988

\begin{tabular}{|c|c|c|c|c|c|c|c|}
\hline & $\mathbf{1 9 7 0}$ & $\mathbf{1 9 7 1}$ & $\mathbf{1 9 7 2}$ & $\mathbf{1 9 7 5}$ & $\mathbf{1 9 8 0}$ & $\mathbf{1 9 8 5}$ & $\mathbf{1 9 8 8}$ \\
\hline ESCOLAS & 321 & 296 & 268 & 290 & 372 & 411 & 413 \\
\hline ALUNOS & 18.392 & 16.321 & 16.373 & 24.097 & 54.312 & 71.259 & 86.983 \\
\hline
\end{tabular}

Fonte: AZEVEDO (2004, p. 39).

Assim como a educação adventista se adequou às exigências educacionais no período final do regime militar, outros segmentos particulares de ensino também se estruturaram, e avançaram inclusive em 
outros níveis de ensino, como por exemplo o superior. É possível verificar, como apresenta Lira (2010, p. 118), que na década de 1980 houve uma mudança substancial na representação política da escola particular. Segundo ele, "o grupo católico ${ }^{11}$ deixou de ter a hegemonia no movimento privatista na educação, além da redução relativa do número de escolas confessionais no universo das escolas particulares". Ascenderam novas lideranças oriundas de sindicatos patronais que passaram a comandar o movimento das escolas particulares, fragmentando assim em duas correntes representativas da educação particular — as confessionais e as não confessionais, porém ambas de ensino privado.

Embora o número de escolas adventistas não tenha aumentado significativamente no período pós Constituição (1988-1996), com base na nova estrutura criada a partir das escolas fundamentais (professores titulados, terrenos adequados, amplas instalações, equipamento moderno e qualidade de ensino), surgem as condições necessárias para a implantação do ensino médio. Em 1996 a instituição possuía 477 unidades escolares, das quais, 61 ofereciam educação básica completa (fundamental e médio), com um total de 104.133 alunos $^{12}$. E esse número duplicou em apenas seis anos, passando para 123 unidades oferecendo o ensino médio no ano de $2002^{13}$.

Embora o aumento no número de unidades, como também no número de alunos ${ }^{14}$ mostrava o avanço que a instituição alcançava no cenário nacional, essa perspectiva trouxe algumas preocupações para a denominação. Com o aumento do número de unidades escolares, a diversificação de programas na educação básica e o aumento do número de alunos, o que se percebeu foi uma miscigenação na composição de professores e alunos. Quanto mais aumentava o número de unidades e alunos, diminuía o percentual de

11 Apesar de ser mais representativo, não era o único segmento educacional confessional, contudo, os demais não tinham representação política e nem expressão numérica diante do crescimento da privatização do ensino por grupos estabeleciam uma visão financista para a educação em contraponto a visão ideológica religiosa da educação confessional.

12 Dados obtidos em AZEVEDO, P. Revista Educação Central Brasileira. Artur Nogueira, SP: UCB Jan/mar de 2002. 13 Idem.

14 Em 2010 os relatórios oficiais da instituição apresentavam uma matrícula de 186.420 alunos em 357 unidades escolares no território brasileiro. 
alunos filhos de membros da igreja, como também o aumento percentual de professores que não confessavam a mesma fé.

Essa miscigenação cultural colocou em cheque os princípios filosóficos educacionais da instituição. Se de um lado existe a preocupação com o ideário educacional institucionalizado, e se busca crescer em qualidade educativa, sem perder a filosofia que sustentou essa educação, por outro lado, pode-se dizer que é impossível estar inserido num contexto cultural e social sem receber a influência dessa cultura imposta e praticada, o que gerará rupturas no processo de desenvolvimento institucional.

A conclusão que este estudo apresenta é que a educação adventista procura manter suas raízes filosóficas em um ideário educacional vigente e atual, porém, não é possível deixar de analisar que rupturas com o seu ideário estão presentes e podem definir se o pêndulo moverá mais para permanecer ou distanciar-se do ideário estabelecido.

\section{Considerações finais}

Reis (2009, p. 101), ao apresentar suas pesquisas sobre o tempo e a história, diz que o tempo social é diferente do tempo cronológico, já que "o cálculo do tempo social é essencialmente descontínuo". E essa descontinuidade é perceptível em todo o processo de construção da educação adventista, desde seus primórdios embrionários até o processo de transformação em uma rede de ensino.

O tempo social também é caracterizado por avanços e retrocessos, por conquistas e perdas, mas é esse tempo social que permite a construção de uma identidade social. Vale relembrar o pensamento de Walter Benjamim sobre o tempo histórico rompido e reconstruído, citado por Dosse (2012, p. 181-183) recordando que "o passado é contemporâneo do presente, pois o passado constitui-se ao mesmo tempo que o presente: passado e presente sobrepõem-se e não se justapõem. São simultâneos e não contíguos". E é essa similaridade temporal que auxilia a compreensão de um começo e consolidação de uma rede educacional identificada como educação adventista.

A partir do contexto histórico até aqui apresentado é possível verificar que o desejo da denominação em ter em sua matriz missiológica 
a educação como um dos meios de divulgação da fé e doutrina adventista foi alcançado. Os dados indicam que, desde de sua origem, até o final do período analisado, houve uma expansão em abertura de unidades e aumento de número de alunos, o que caracteriza a permanência da matriz educacional como uma das frentes evangelizadoras da denominação.

Durante o período de estruturação da educação no Brasil vários foram os embates relacionados ao público e o privado na educação. Os lados opostos sempre estiveram em constante conflito, contudo, a história mostrou que, até o momento analisado, a educação confessional manteve seu espaço de atuação, com ampliação de sua influência em determinados momentos históricos, ou mesmo de retração desse espaço, porém, nunca perdeu a oportunidade de manter uma educação diferenciada àqueles que desejavam uma educação religiosa em detrimento da educação laica, mesmo que isso significasse uma elitização do ensino em questão.

É possível compreender que, em decorrência de uma estruturação das políticas educacionais do Brasil nos anos iniciais de 1970, com a Lei 5.692/71, a educação adventista precisou romper com os paradigmas educacionais da época, e adaptar-se a uma nova realidade educacional, o que gerou o fechamento de unidades escolares, mas, ao mesmo tempo, oportunizou o crescimento em qualidade pedagógica e na consolidação de uma rede de ensino.

Outro fator relevante que a análise histórica do período estudado até aqui apresenta é que a educação adventista, a partir dos anos de 1970, começa a disputar espaço com outros segmentos de ensino privado que não o confessional. Isso faz com que a educação saia do escopo religioso/ confessional e passe a ser compreendido como um serviço educacional. Deixa de ser um processo de formação religiosa para um comércio do ensino, oriundo das políticas neoliberais dos anos 1980-1990, cuja influência esteve presente tanto no segmento privado como público da educação. A adaptação a essa nova maneira de entender a educação gera uma adaptação e a abertura da educação adventista para atender também um público não relacionado com a fé da denominação. 


\section{Referências}

AZEVEDO, P. Bosquejo histórico da criação de ensino médio em instituições adventistas no Brasil. Revista Educação Central Brasileira, São Paulo, UCB, jan./mar. 2002. AZEVEDO, R. Projeto Brasil. São Paulo: Gráfica União Sul Brasileira, 1973.

AZEVEDO, R. O Ensino adventista de nível fundamental no Brasil. In: TIMM Alberto, Org. A Educação Adventista no Brasil - Uma história de aventuras e milagres. Engenheiro Coelho: UNASPRESS, 2004.

DOSSE, F. A História. São Paulo: Editora Unesp, 2012.

GREENLEAF, F. Terra de esperança: o crescimento da Igreja Adventista na América do Sul. Tatuí: Casa Publicadora Brasileira, 2011.

GROSS, R. Colégio Internacional de Curitiba - Uma história de fé e pioneirismo. Rio de Janeiro: Collins, 1996.

HOSOKAWA, E. Da Colina, "Rumo ao mar". Colégio Adventista Brasileiro Santo Amaro —1915-1947. Dissertação (Mestrado) — Universidade de São Paulo, São Paulo, 2001.

KRÄMER, P. Our School at Curityba. The Missionary Magazine, v. XI, n. 6, p. 256, jun. 1909.

LIRA, A. T. Nascimento. A legislação da educação no Brasil durante a ditadura militar (1964-1985): um espaço de disputas. Tese (Doutorado) — Universidade Federal Fluminense, Instituto de Ciências Humanas e Filosofia, Departamento de História, Rio de Janeiro, 2010.

LUTERO, M. Aos conselhos de todas as cidades da Alemanha para que criem e mantenham escolas cristãs [1524]. In: Martinho Lutero: obras selecionadas. São Leopoldo: Comissão Interluterana de Literatura, 1995, v. 5. p. 299-325.

MARTINE, G. As migrações de origem rural no Brasil: uma perspectiva histórica. In: Fundação Seade. História e população: estudos sobre a América Latina. São Paulo: Fundação Seade, 1990.

OLIVEIRA, M. M. Os empresários da educação e o sindicalismo patronal: o sindicato dos estabelecimentos de ensino no Estado do Rio de Janeiro (1944-1990). Bragança Paulista: EDUSF, 2002. 
PEVERINI, H. J. En las huellas de la Providencia. Buenos Aires: Casa Editora Sudamericana, 1988.

RABELLO, J. John Boehm, educador pioneiro. São Paulo: Centro da Memória Adventista, UNASP, 1990.

REIS, J. C. História, a ciência dos homens no tempo. Londrina: Eduel, 2009.

SCHULZ, T. W. O valor econômico da educação. Rio de Janeiro: Editora Zahar, 1967.

SOUZA, R. M. S. Deutsche Schule, a Escola Alemã de Curitiba: um olhar histórico (1884-1917). Tese (Doutorado em Educação) — Universidade Federal do Paraná. Curitiba, PR: UFPR, 2006.

STENCIL, R. História da educação superior adventista: Brasil, 1969-1999. Tese (Doutorado em Educação) — UNIMEP. Piracicaba: EDUNIMEP, 2006.

VIEIRA, R. C. C. Vida e Obra de Guilherme Stein Jr. : Raízes da Igreja Adventista do Sétimo Dia no Brasil. Tatuí: CPB, 1995.

VIEIRA, R. C. de C. Primórdios criacionistas da educação adventista no Brasil: destacando a contribuição de um pioneiro. Brasília: Sociedade Criacionista Brasileira, 2011.

WEBER, M. Ética Protestante e o Espírito do Capitalismo. São Paulo: Companhia das Letras, 2007.

Recebido: 27/05/2016

Received: 05/27/2016

Aprovado: 19/06/2016 Approved: 06/19/2016 